\title{
Development and Application of Film Laminated Metal Composite Decorative Panel
}

\author{
Yujun LIU*, Shunli LIU, Shuai WU, Tingting LIU, Feilong SUN \\ China Building Material Test \& Certification Group Co., Ltd \\ State Key Laboratory of Green Building Materials \\ Beijing, China \\ e-mail: 1yj@ctc.ac.cn, 1s1@ctc.ac.cn, wushuai@ctc.ac.cn, ltt@ctc.ac.cn, sfl@ctc.ac.cn
}

\begin{abstract}
This paper highlights the production process, performance feature and engineering application of film laminated metal composite decorative panel, on the basis of introducing film materials. The development prospect of the product is broad by virtue of its excellent product performance and advantage of environmental protection in production.
\end{abstract}

Keywords-film laminated metal composite decorative panel; Production process; Performance

\section{PREFACE}

With the rapid economic development in China, for the advantages like light weight, high specific strength and plentiful decoration effect of metal composite decorative products, the consumption of them grows rapidly and their application field is wide. A large amount of metal composite decorative products, from the traditional ones like aluminumplastic board, aluminum veneer, color steel board, aluminum honeycomb board, aluminum profile, etc. to the emerging ones in recent years like metal-decorative insulation board, foamed aluminum board, titanium-zinc composite board, copper-plastic composite board, sun louver, etc., are used on numerous urban large-scale buildings, which is a beautiful landscape of cities.

Generally, coating is used to paint on the surface of metal composite decorative products to realize the decorativeness of the product and strengthen the resistance to corrosion and weather of metal board. In recent years, with the national and local governments putting forth effort to solve air pollution problems, various policies and regulations strictly restricting the discharge of VOC are continuously issued. Against this background, the regular production and tax and fee cost of a large amount of enterprises of metal coating and metal decorative products are strongly affected by the policies, and product innovation and technology upgrade are urgently needed. At the general background that film materials develop rapidly, product category is increased and durability is improved, film materials are used in metal composite decorative boards for building, film laminated metal composite decorative products develop rapidly and have been used in indoor and outdoor decoration engineering in large amount.

Film materials, as critical materials of film laminated metal composite decorative panels, are introduced as follows:

\section{FILM MATERIALS}

Wherever Times is specified, Times Roman or Times New Roman may be used. If neither is available on your word processor, please use the font closest in appearance to Times. Avoid using bit-mapped fonts if possible. True-Type 1 or Open Type fonts are preferred. Please embed symbol fonts, as well, for math, etc.

\section{A. Vinyl Overlay Film}

Vinyl overlay film is thermoplastic resin film made by adding plasticizer, thermal stabilizer, colorant, etc. into vinyl resin, with wide selection range in terms of compounding agent and necessary service performances like mechanical property obtained by controlling mixture ratio. Polyvinyl chloride (PVC) film is made of polyvinyl chloride resin plus other modifier through calendering process or blow molding process, with the general thickness of $0.08 \sim 0.2 \mathrm{~mm}$. Polyvinyl chloride film may roughly be classified into two types, i.e. plasticized PVC film and unplasticized PVC film. Plasticized PVC is generally used in floor, ceiling and surface layer of leather, but its application scope is limited for it contains softening agent, is prone to embrittling and difficult to preserve. Unplasticized PVC does not contain softening agent, so its flexibility is good; it is easily formed, not fragile, nontoxic, pollution-free and can be preserved for a long time. The products are used in building materials industry, packaging industry, pharmaceutical industry and other industries, with the largest percentage in building materials industry, accounting for $60 \%$, followed by packaging industry, and then other industries in which the application scope is small.

\section{B. Polyester Overlay Film}

The thermoplastic polyester resin generally used may be classified into polyterephthalate (PET), polybutylene terephthalate (PBT), etc., among which, PET had been produced as early as 1940 s. For PET film, the transparency is good, it is lustrous, the air tightness is good, the mechanical property is excellent, its obdurability is the best among the thermoplastics, the tensile strength and shock strength are higher than that of general films, its heat resistance, cold resistance, chemical resistance and fuel resistance are excellent, while it is not resistant to strong alkali. PET raw materials are made into thin board through fusion and squeezing, and then made into film by being extended 
longitudinally by 3 4 times with longitudinal-direction elongator, preheated, transversely extended by 3 4 times, subjected to heat treatment and cooling. PET thin board without extensional deformation is white chaotic and crisp, and after it is extended in longitudinal and transverse directions, its internal structure is improved, and its mechanical property and thermal property are excellent.

\section{Allyl Resin Overlay Film}

Allyl resin, in broad sense, is contained in polymethacrylate, and copolymer mainly containing methyl methyacrylate (PMMA) is generally used. It had been produced in 1930s, with which the film is formed through extrusion. PMMA resin, characterized by good weather resistance and being colored easily, may be made into colorless films and films in various colors.

\section{Fluoro Resin Overlay Film}

Fluoro resin in broad sense refers to high copolymer with its molecule containing fluorine element. Fluoro resin in narrow sense refers to the resin obtained by replacing the hydrogen atom in polyethylene and its inducer with fluorine atom. Fluoro resin is one of the most stable and weatherproof materials, fluorocarbon bond has very high bond force, and fluoro resin always has excellent ability resisting ageing caused by light, heat, humidity, acid-base, organic matter and the like as well as resisting corrosion. Because the characteristic of the material itself and the limitation in processing technique, not all fluoro resins may be processed into thin film materials with thickness of tens of micrometers. At present, widely used fluorocarbon films are mainly PVF, PVDF, FEP, ETFE, etc. Thereinto, for full-fluorine films like FEP and ETFE, although with excellent performance, it is difficult for them to satisfy the decorative effect for their surface energy is low, it is difficult to compound, they cannot be stably compounded with metal board and there is only white. At present, the most common mainstream products are PVF film and PVDF composite film.

In order to obtain more excellent product features and meet the application requirements of metal composite decorative materials in a better way, besides single film, most of film products are composite film, e.g. PVDF system film, PVDF or PVDF/PMMA co-extruded transparent resins are adopted for upper part transparent surface layer, high light-resistant and color-protecting ACR printing ink for middle plating layer and PMMA (ACR) or PVC modified color resin for bottom color layer; a multilayer compound decorative film has good economical efficiency, function and is rich in color.

\section{PRoduction PROCESS OF FILM LAMINATED METAL COMPOSITE DECORATIVE PANEL}

Base boards commonly used for film laminated metal panel are galvanized steel board, aluminized and galvanized steel board, aluminum-, magnesium- and zinc-plated steel board, stainless steel board, aluminum board and aluminummagnesium-manganese board. See Figure 1 for typical process flow of metal board overlay film, with the main procedures including base metal unwinding, pretreatment, adhesive painting, bottom surface treatment, film compounding, protective film compounding and winding. Film is compounded onto the base metal through adhesive that possess very strong adhesive bonding force and aging resistance. Correct selection of adhesive has important influence on product performance and service life of film laminated metal board, and attention must be drawn to type selection of adhesive used for film laminated metal composite decorative panel.

After unwinding, the base metal is subject to surface cleaning, passivation and other pretreatment process firstly, so as to remove surface contamination, improve surface adhesion and improve corrosion resistance. Subsequently, paint adhesive on the matal surface and determine whether to apply back paint on the bottom surface as required. Then, heat the metal board through an oven and dry the solvent in adhesive and back paint; as for dry film composite mode where the adhesive excludes solvent, the purpose of the procedure is to heat the base board to achieve the composite temperature of dry film adhesive. In film composite process, the film is compounded on the metal surface of coated adhesive by a press roller, which is required to impose certain pressure so that the film and base metal are adhered firmly. Double-component solvent adhesive is required to be cured in the drying room after compositing to achieve higher adhesive strength, while the curing process in the drying room is unnecessary for the compound of thermal activation adhesive and dry film composite mode, which could improve the production efficiency and reduce the production cost. After compositing, the film surface is required to apply a layer of protective film to protect the surface and avoid damage during transportation and processing.

The film laminated metal panel is finally supplied to the downstream manufacturer in the form of metal coiled material for producing and manufacturing metal composite decorative panel products.

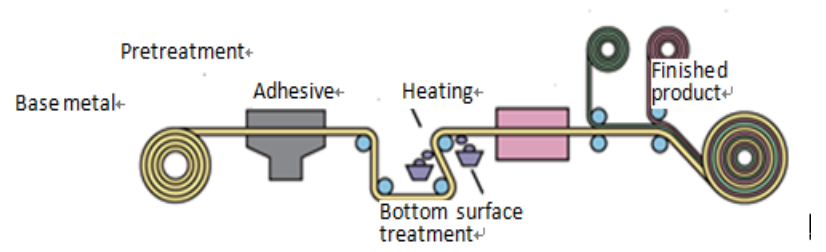

Figure 1. Schematic diagram for production process of film laminated metal panel.

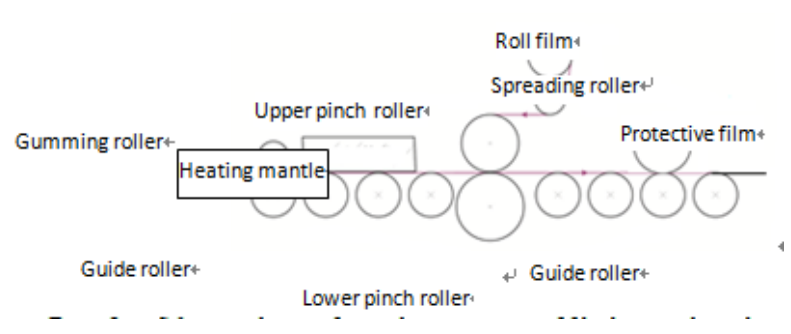

Figure 2. Schematic diagram for production process of film laminated metal composite panel

For the actual production of film laminated metal composite decorative panel, in addition to the above- 
mentioned typical production modes, there are also production modes of films laminated the metal composite decorative original board (the composite board that the metal base board is generally pretreated but not coated). Such mode includes that the metal composite decorative original board is subject to such process as heating, gumming, coating, (curing) and coating, etc., as shown in Figure 2.

\section{Performance Feature of Film Laminated Metal Composite Decorative Panel}

Film laminated metal decorative composite panel has the advantages of both film material and metal composite board, and has excellent product performance. The film material may be compounded with steel boards and aluminum alloy boards, and may also replace the surface coating of aluminum-plastic composite board, aluminum honeycomb sheet, aluminum corrugated composite board and metal decorative insulation board to composite decorative board on the $\mathrm{f}$ metals such as film lamiknated aluminum-plastic composite board etc. Take fluorocarbon film laminated steel panel as an example, and its main performance features are as follows:

\section{A. Decorativeness}

The fluorocarbon film has different colors and patterns such as monocolor, multicolor and decorative pattern (marble grain, wood grain, etc.), and may also be made into decorative surface with concave-convex sense and other simulation textures, which could meet various inspirations of creation and requirements of the designer and has rich decorative effect.

\section{B. Chemical Resistance}

Coating on the surface of metal composite decorative board not only obtains decorativeness, but also effectively protects the metal base board from corrosion, and the chemical resistance is very important. In the process of coating, due to the influence of such factors as impurity, lowboiling mixed solvent, thickness homogeneity and process stability, it is liable to generate such defects as pores, pinholes and cracks, which make acid-base and other chemicals liable to be impregnated into metal board surface and cause corrosion. Defects such as pinholes and cracks can be effectively avoided during the process of film materials production, which may effectively obstruct chemicals penetration and protect metals from corrosion for a long time. As shown in Figure 3, after soaking PVF film laminated metal panels and PVDF stoving varnish steel boards into 5\% of sodium hydroxide and 5\% of hydrochloric acid for 30 days, the soaking part of PVDF stoving varnish steel boards generates obvious bubbles, which indicates PVDF stoving varnish steel boards fail to effectively obstruct penetration and corrosion of acid-base to metals, causing steel boards are eroded by acid-base, thus generates blistering phenomenon. Whereas no change is made for the soaking part of PVF film laminated steel boards.

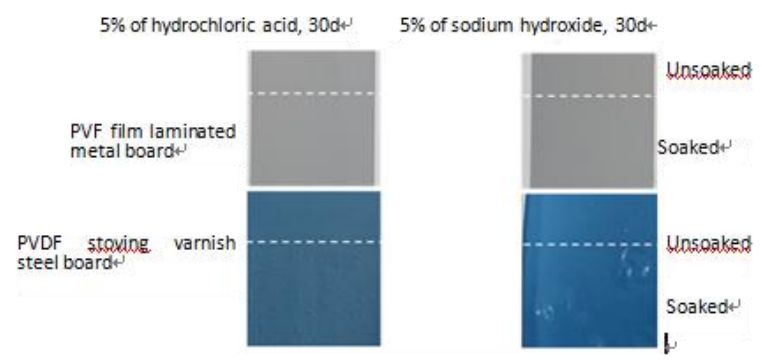

Figure 3. Comparison on Acid-base Resistance Performance of PVF Film Laminated Steel Board and PVDF Stoving Varnish Steel Board (Source: DuPont)

\section{Processability}

Fluorocarbon film has excellent processability and extensibility, and the PVF film laminated metal panel will not crack or delaminate even under 0T bending operation. Observe the bending surfaces under a 40x microscope after the fluorocarbon film laminated steel board (gray) and two types of PVDF baking steel boards (white) undergo the 0T bending operation. As shown in Figure 4, obvious cracks can be seen on the coating surface of fluorocarbon paint, while no cracks are observed on the surface of fluorocarbon film.

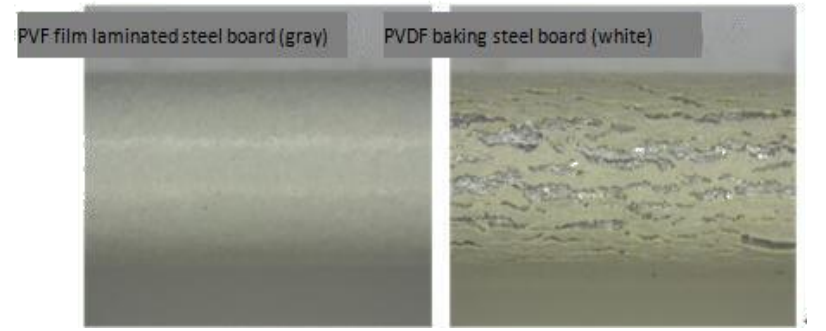

Figure 4. Comparisons of Film laminated Steel Board and Baking Steel Board after subjecting to 0T Bending (40x Magnification, Source: DuPont).

Existence of cracks is liable to cause rust and corrosion of the metal boards, thus affects the service life of building structure.

\section{Wearability}

Compared with coating, fluorocarbon film is denser and tougher, and with better wearability, it is less susceptible to sand abrasion.

\section{E. Easy to Cleaning}

The building surfaces shall be kept permanent clean and beautiful and shall avoid accumulation of haze, dust, ash, exhaust and other dirt in the air. Fluorocarbon film has good characteristics of non-stick and stain-resistant, which can greatly reduce the cleaning and maintenance cost of the building.

Take photos and sample for the fluorocarbon film, fluorocarbon paint coating and acrylic paint coating samples after 2.5 years of outdoor placement (United States), as shown in Figure 5, the result shows that fluorocarbon film is more resistant to contamination than fluorocarbon and acrylic paint coatings. 


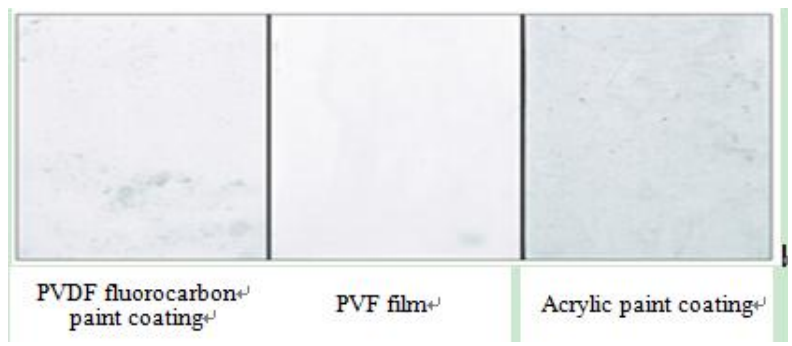

Figure 5. Result of Outdoor Stain Resistance Test.

(Place for 2.5 Years Outdoors, United States, Source: DuPont)

\section{F. Weatherability}

The weatherability of coatings, films and other products is determined by the type of polymer resin, the resin system and the weathering-modified filler system in the products. As the most stable and durable polymer material, the weatherability of fluorine material is generally recognized by the industry, and coating and film products made of fluororesins have inherent advantages of weather resistance. Defects such as pinholes and cracks are effectively avoided during the process of film materials production, which makes its weatherability more prominent.

\section{ENGINEERING APPLICATION OF FILM LAMINATED METAL COMPOSITE PANEL}

With its excellent performance characteristics and a variety of surface effects (wood, marble, granite, brick, imitation stainless steel wire drawing, camouflage, etc.), film laminated metal composite decorative panel has been applied in the fields of construction, furniture, transportation, home appliances, etc., its typical products are as follows:

Construction: internal and external walls, roofs, partitions, ceilings, wallboards of plant, etc.

Furniture: wardrobes, dining tables, chairs, tea tables, clothes lockers, file boxes, bookshelves, office cabinets, etc.

Door industry: rolling shutters, security doors, garage doors, interior doors, door frames, window frames, etc.

Transportation: interior decorative board of the car, train partition and interior decorative board, ship compartment and interior decorative board, etc.

Home appliances: refrigerators, freezers, washing machines, air conditioners, fans, lamps, solar water heaters, electric water heaters, etc.

Office: vending machines, computer shells, switch cabinets, instrument cabinets, tool cabinets, elevator interiors, etc.

With the increase of design and color of coating products and the improvement of their performance as well as with the environmental protection advantages such as low VOC emission of compound production process, the film laminated metal composite decorative panel must have broad prospects in application and great potential in future development.

\section{REFERENCES}

[1] SUI Xue-bin,HE Chang-sheng,SHEN Feng, Study of performance of adhensive for film/steel laminating, Adhesionin China. 4 (2015) 6971 . 